\title{
Adaptive support ventilation as an acceptable mode to prevent airflow limitation, air entrapment, dynamic hyperinflation and patient-ventilator dyssynchrony
}

\author{
A Taha ${ }^{1 *}$, A Shafie $^{1,2}$, Y Lavoie $^{3}$, H Hubert $^{1}$, R Marktanner $^{1}$ \\ From ESICM LIVES 2015 \\ Berlin, Germany. 3-7 October 2015
}

\section{Introduction}

Adaptive support ventilation (ASV) is a dual control mode, using measured dynamic compliance and time constant, with an automated adjustment of tidal volume and respiratory rate combined to meet the preset minute ventilation. The purpose of this study was to evaluate the effectiveness of (ASV) in restoring air flow stability, decrease work of breathing and improving dyssynchrony in ventilated patients with variable airway resistance.

\section{Methods}

20 ICU patients showing air entrapment, Dynamic Hyperinflation and patient-ventilator dyssynchrony were enrolled between january 2014 and March 2015. Data was collected 48 hours after switching to ASV, which was applied with the same protocol. All enrolled patients were hemodynamically monitored. A retrospective analysis of this data was performed.

\section{Results}

Completed data sets were obtained from 20 patients. the average peak airway pressure was $28 \mathrm{~cm} \mathrm{H2O}$. Peak airway pressure decreased $19 \%(\mathrm{p}<0.01)$, flow time curves improved by $80 \%(\mathrm{p}<0.001)$, with decrease work of breathing $(\mathrm{p}<0.015)$ over short time from starting the patient on ASV mode.

\footnotetext{
${ }^{1}$ Division of Adult Cardiac and Transplant Critical Care, Critical Care Department, Sheikh Khalifa Medical City Managed by Cleveland Clinic, Abu Dhabi, United Arab Emirates

Full list of author information is available at the end of the article
}

\section{Conclusions}

In our patient series, ASV significantly improved dyssynchrony by using measured dynamic compliance and time constant cycle by cycle with subsequent optimization of flow time curves with less use of sedation and neuromuscular blockage. Furthermore, this strategy improved hemodynamics and facilitated weaning from MV. Therefore, our data suggests, that this ventilation modality has favorable results and appears to be an effective tool in patients with air flow resistance, who develop air entrapment, Dynamic Hyperinflation and patient-ventilator dyssynchrony during their ICU stay.

\section{Authors' details}

${ }^{1}$ Division of Adult Cardiac and Transplant Critical Care, Critical Care

Department, Sheikh Khalifa Medical City Managed by Cleveland Clinic, Abu Dhabi, United Arab Emirates. ${ }^{2}$ Division of Respiratory Therapy, Respiratory Therapy Department, Sheikh Khalifa Medical City Managed by Cleveland Clinic, Abu Dhabi, United Arab Emirates. ${ }^{3}$ Division of Respiratory Therapy, Respiratory Therapy Department, Abu Dhabi, United Arab Emirates.

\section{Published: 1 October 2015}

\section{References}

1. Branson RD, Chatburn RL: Controversies in the critical care setting Should adaptive pressure control modes be utilized for virtually all patients receiving mechanical ventilation? Respir Care 2007, 52:478-485, discussion 485-78.

2. Jaber S, Delay JM, Matecki S, et al: Volume-guaranteed pressure-support ventilation facing acute changes in ventilatory demand. Intens Care Med 2005, 31:1181-8.

doi:10.1186/2197-425X-3-S1-A826

Cite this article as: Taha et al:: Adaptive support ventilation as an acceptable mode to prevent airflow limitation, air entrapment, dynamic hyperinflation and patient-ventilator dyssynchrony. Intensive Care Medicine Experimental 2015 3(Suppl 1):A826.

\section{SpringerOpen ${ }^{\circ}$}

(C) 2015 Taha et al.; This is an Open Access article distributed under the terms of the Creative Commons Attribution License (http:// creativecommons.org/licenses/by/4.0), which permits unrestricted use, distribution, and reproduction in any medium, provided the original work is properly cited. 